\title{
Needs escalate, capacity stagnates in Syria
}

$\mathrm{T}$ he humanitarian response to the Syrian Arab Republic's twoyear-old civil war is "woefully" inadequate and requires a "massive scale-up" by international aid agencies, says Médecins sans Frontières (MSF) Canada.

Some 70000 people have died in the war — including 130 physicians but the gutting of the country's health care system has also caused many unseen casualties.

There is a "large number of spontaneous abortions, early deliveries, [and] folks on dialysis, slowing dying without access to care," Stephen Cornish, executive director of MSF Canada, told CMAJ in an interview.

"This was a middle-income country," says Cornish, who returned from Syria April 2 following two weeks of reconnaissance. "Now regular health needs are not met. Under twos are not vaccinated, and that's another story waiting to happen. There are health risks from typhoid. There's scabies, overcrowding and unsanitary conditions."

There are also many shortages: fuel for generators, ambulances, drugs, surgical supplies, blood, and the list goes on. The humanitarian response is "woefully unable to meet the needs," says Cornish. "We couldn't cope with the winter needs. Now we're unprepared to deal with the summer. We need a massive scale-up."

MSF is also calling on other nongovernment agencies and the international community to ramp up activities and ensure care to civilian and military casualties.

"We need unhindered access and funding. The casualties of war and the internally displaced people have a right to health care and basic needs. A right," he says.

Though the International Committee of the Red Cross is active in Syria, the Syrian government in Damascus has denied MSF permission to work in the country, despite repeated requests. Nonetheless, MSF has opened four hospitals in opposition-held areas in the

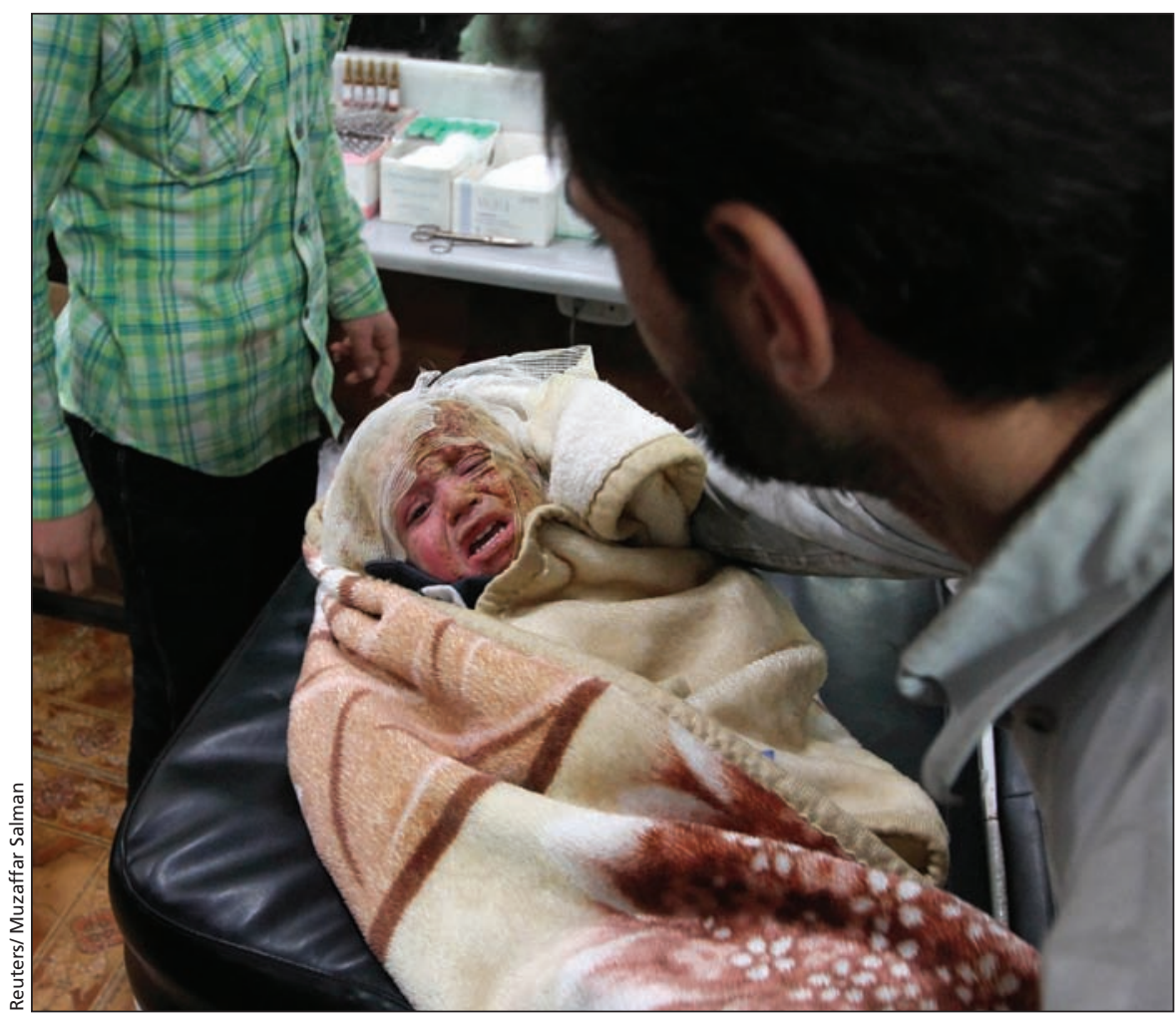

Burns are common, because people are not used to the higher-octane fuel coming in from Iraq. Here, a man carries a baby burned by heating fuel into a field hospital in Aleppo.

north, and plans to open two more. MSF has also trained 50 government and nongovernment health workers. In total, MSF has 500 staff in the area.

Meanwhile, in addition to caring for those wounded in the conflict, MSF is seeing an increasing number of patients with nonwar-related medical conditions. Burns are common, because people are not used to the higher-octane fuel coming in from Iraq.

"We've become the burn clinic in Northern Syria," says Cornish.

That clinic has been the scene of heart-breaking triage decision. One patient with diabetes needed a double amputation of his feet because of gangrene. "But to do that would have put the burn patients at risk of infections," says Cornish. "There was nowhere for him to go and chances are in a few weeks it will be an emergency and he will die. It's a very tough decision."
The Red Cross, which works with the Syrian Arab Red Crescent in both government- and opposition-held territories, reports that reaching hospitals in areas such as Aleppo and Deir Ezzor is a challenge, leaving patients vulnerable.

"Left untreated, even a slight injury can become very serious or even fatal," Dr. Andrea Reis, who coordinates the Red Cross's health activities in Syria, said in a news release.

Meanwhile, the legions of internally displaced persons and refugees grow daily. The United Nations reports an estimated 2.5 million internally displaced Syrians, although the Syrian Arab Red Crescent estimates that number now exceeds 3.6 million in this country of 20 million.

Many people have no shelter or live in schools or tents with another family.

"There are large pockets of civilian population with no power, no water, 
high co-living and high fuel costs," says Cornish. "The scale of need is really off the charts. Some of the worse we can't even get to."

In addition to internally displaced persons, 975000 Syrians have fled to neighbouring Lebanon, Jordan, Turkey and Iraq according to the United Nations. Cornish believes the actual number may be higher, because many refugees are unwilling to be documented.

Conditions in camps are difficult. An MSF survey in December indicated half the Syrian refugees in Lebanon were not receiving required medical treatment because they could not afford it.

In one case, a woman needed a cesarean section, but "the cost in Lebanon was \$800," says Cornish. “It might as well have been a million. So she was considering going back to the war zone to give birth. Think of the desperation, considering going back to a war zone."

People in the refugee camps "are selling their assets, marrying off daughters to pay for food and an apartment," he adds.

MSF is providing medical care, including surgery and mental health services, as well as nonfood items like stoves and charcoal. "We would normally not be working in refugee camps chlorinating water and taking care of sanitation, but this is an emergency within an emergency," says Cornish.

By the end of 2013, the United Nations expects one million refugees will have entered each of Syria's neighbouring four countries, for a total of nearly one-fifth of the country's population. - Barbara Sibbald, CMAJ

CMAJ 2013. DOI:10.1503/cmaj.109-4493

Editor's note: This is the second of a three-part series on Syria. Go to cmaj.ca to read the first article ("Physicians, health facilities targeted in war-torn Syria"). 